\title{
"When She Plays We Hear the Revolution": Girls Rock Regina - A Feminist Intervention
}

\author{
Charity Marsh \\ University of Regina \\ Charity.Marsh@uregina.ca
}

\begin{abstract}
In this article, I analyze the ways in which community-based arts projects have the potential to challenge the gendered power dynamics of the music industries by creating productive spaces that encourage accessibility, promotion of female artists, and connection amongst girls and female-identified professionals. Specifically, I share my reflections on the inaugural Girls Rock Regina (GRR) camp, which took place in July 2017 in Regina, Saskatchewan, Canada. Drawing on interview data collected from the GRR organizing crew, participating musicians, volunteers and campers, as well as from my participatory experience as Canada Research Chair in Interactive Media and Popular Music, and Director of the IMP Labs whose research often focuses on community arts-based research in popular music genres and creative technologies, I highlight the ways in which hegemonic ideas around the gendering of creativity, music technologies, and the music industries are being challenged.
\end{abstract}

KEYWORDS: Feminist Interventions, Strategies for Empowerment, Girls Rock Regina, Collective Experience, Feminist Popular Music

\section{Girls Rock!}

I think we are in environments a lot of the time where our knowledge is consistently not valued - and even talking about this is hard. We get told a lot that it's not about our gender [...] and yet all of us who are teaching at this camp, have had the same experiences, and so there's a common denominator that can't be denied. (Beth, GRR Bass Instructor 2017) ${ }^{1}$

It is widely recognized by feminist scholars and female performing artists that women within the popular music industries continuously face blatant and insidious acts of sexism that can thwart their creative efforts, and (re)produce unequal 
gendered power relations (see O'Brien 2016; Rodgers 2010; Marsh 2003, 2007, 2009, 2019; Downs 2012). Drawing on Cloonan, Homan, and Cattermole's (2015) work, I am employing the term 'music industries' as a way to unpack the notion of a music industry as monolithic entity, and to highlight the multiple aspects and processes that are included when one participates in such complex systems. In the current moment of the \#metoo and \#timesup campaigns, it has become vital for the music industries (including those participants who are in positions of power) to be accountable for the attitudes, corruption, gender violence, and the ongoing subjugation of women and girls that maintain and celebrate the status quo, limiting the ways in which women and girls are allowed to participate. As highlighted by GRR Bass Instructor Beth in the quotation above, it is becoming more difficult to deny the negative consequences of the persistent boys' club. The \#metoo campaign has clearly demonstrated the ubiquity of sexual harassment and gender-based violence across the board. This campaign has led to conversations which expose the clear ways in which women and girls are marginalized, and valued less for the same work, all while their ideas and contributions are trivialized and not taken seriously. For women working within the music industries this campaign has ignited a fire for change.

In her blog post, "Don't Call Me Honey: In 2017, Women Confronted the Deep Roots of Rock's Boys Club", National Public Radio music critic and author Ann Powers reminds us why there is still such a need for this kind of activism. She argues,

There is much more to do. Kesha lost in court against Dr. Luke, even if she won in popular opinion. The year's top-selling rock acts are still all-male bands. Rock needs to remake itself in new shapes, within new communities, if it is to thrive as a space of genuine equality and freedom. More women need to lead, not just as the faces and voices of rock and roll, but as its producers, it engineers, its tour managers, its architects. Girls not just to the front, but everywhere! (Powers 2017)

For real change to occur, it is critical to acknowledge and build on the herstories of action that have been at the heart of how women have participated within the music industries or found meaningful ways to articulate and create sincere popular music identities. Reflecting upon community-based, grass roots initiatives that highlight inclusion, performance, and a DIY aesthetic for girls and female-identified people, is critical as the music industries come under pressure to reflect and change.

In this article, I look to Girls Rock Camp, an initiative which has grown into the Girls Rock Camp Alliance that now boasts almost 100 organizations worldwide. Created by Misty McElroy, a women studies major at Portland State University, the camp started in 2000 as a grass roots, community-based girls rock camp held at Portland State University. McElroy's initial camp, which had no financial backing, led to an after-school program, Ladies Rock Camp, an internship program, and a record label (see Kay 2017, 145). Girls Rock Camps offer the potential to challenge the gendered power dynamics within the music industry by creating productive spaces that encourage accessibility, promotion of female and female-identified artists, and connection amongst girls and female professionals, as well as featuring women and female-identified persons as performers, instrumentalists, technicians, engineers, organizers, managers, et cetera. More specifically, in this work I share my reflections on the inaugural Girls Rock Regina (GRR), which took place in July 2017 in Regina, Saskatchewan, Canada. Similar to Girls Rock Camps taking place in several different countries, the fundamental goals of GRR are to harness creativity 
through music as a means to create personal and social change and to actively expand opportunities for girls, women, and female-identified people in heavily male-dominated musical industries. Sharing excerpts from interviews, a roundtable discussion, and participant observations conducted at GRR, I reflect on the strategies female-identified musicians and organizers employ to empower girls and themselves in popular music technologies and industry roles. Focusing on the interview data collected from participating musicians, organizers, volunteers, and campers, as well as secondary sources, such as the recent documentary Play Your Gender (2016), and Sarah Dougher's and Lucy O'Brien's chapters from Voicing Girlhood in Popular Music: Performance, Authority, Authenticity (2016), I illustrate the ways in which hegemonic sexist ideas around the gendering of creativity, music technologies and popular music industries are challenged by Girls Rock Regina's participants.

\section{Being Loud. Being Heard.}

Eventually it just became about making noise and getting them to actually be comfortable being loud. (Jay Kovach, GRR Guitar Teacher 2017)

In the following passage, Judith Butler makes the argument for the possibility of challenging and/or transforming what constitutes norms and the very frameworks within which truths are recognized. Butler states:

What I can be quite literally is constrained in advance by a regime of truth which decides in advance what will and will not be a recognizable form of being [...] [T] his does not mean that a given regime of truth sets the invariable framework for recognition: it means only that it is in relation to this framework that recognition takes place or the norms that govern recognition are challenged or transformed. (Butler 2005: 22)

Historically, there have been many feminist actions and community arts-based initiatives that have sought to do such transformative work within many of the cultural industries. Based on her experience, GRR co-founder Amanda Scandrett concurs: "I work in community arts so I know the importance of utilizing the arts and the power of connecting to the arts for empowerment and for identity, and how beautifully that can work". Community arts and education initiatives focusing on popular music are one strategy for encouraging more girls and women to be involved in the predominantly male music industries. In the article Rebel Grrls in the Classroom: Vocality, Empowerment and Feminist Politics at Rock and Roll Schools for Girls, Alexandra Apolloni (2008) discusses one such initiative, suggesting that for the rock workshop she held the priority was on

expos[ing] [the girls] to modes of expression frequently denied to women, allowing them access to a wide range of musical language through which they could express their own empowered voices, and subvert gender norms in their own, meaningful ways, without feeling inhibited or feeling as through there was a right or wrong way to express themselves. (2008: 4)

Indeed, at the centre of many of these initiatives is an emphasis on girls and women having a voice both literally and figuratively - a voice that is loud and respected. 
When asking the organizers, band coaches, instrument teachers, and volunteers why they became involved with GRR, a common response was what they saw as a real need for more girls and women to feel empowered to take part in the various music scenes, and when participating, to feel like their contributions mattered and were valued. For Amanda, who has been heavily involved in the music scene locally and internationally, she explains, "I work in the industry, in indie rock specifically, and we need more female-identifying, trans and gender nonconforming folks on stage and just making it a normal thing" (Amanda 2017). For Kristina Hedlund of Indie band Rah Rah, and one of the GRR keyboard instructors and band coaches, enabling the campers to find their own voice and creativity is key:

I don't want to shush them a lot and to tell them to be quiet, especially during the band practice. I want them to know that you don't have to be quiet - girls don't have to be quiet - you can be loud and there are no rules, [...] and not, "you're sensitive" and "you shouldn't talk about stuff." It's like Do. Whatever. You. Want. And be loud about it. [...] I talked to [one of the campers] yesterday about this because Riva [Lead Singer and Bassist of Regina rock band, The Spoils] came and did a presentation about genres, and how women going into certain genres, they're told they can't play that type of music, [...] Lots of people are going to tell you, you can't do this, but you have to know that if this is what you want to do, you have to do it and don't let anyone stop you. (Kristina 2017)

The stereotypical codes associated with girls and women "being allowed" to perform certain genres and play specific instruments in gendered ways was addressed throughout a number of the workshops given at GRR. These workshops equipped the campers with the capacity to think critically about how to navigate these situations, the language needed to articulate a critique, as well as some strategies on how to participate outside of these margins.

In her chapter When Loud Means Real: Tween Girls and the Voices of Rock Authenticity, Sarah Dougher (2016: 192) explores how within a Girls Rock environment "the girl's voice came to be identified as both a literal and metaphorical tool for girls' empowerment (that is, presence and agency in the public sphere)." The notion that girls are socialized to take up less space - to be seen, not heard - remains firmly intact in spite of various campaigns throughout the first, second, and third waves of feminism. The deconstructing of such socializations remains an important consideration when trying to address the boys' club nature of the music industries (technical roles, musical genres, engineers, producers, et cetera) and their cultural tentacles (for example award shows, festivals lineups, and performance venues). In Girls Rock camps,

The audible voice is foregrounded in group song, amplified solo singing, screaming (for fun), group discussions, and self-defense classes. The authorial voice (both as an individual and collective endeavour) is emphasized in song writing, zine writing, and other artistic endeavors (poster making, button making, silk screen, etc.). (Dougher 2016: 193)

The emphasis on finding one's voice literally and figuratively, taking up space, and making noise as a key to self-empowerment, was firmly embedded within GRR. Co-founder Danielle Sakundiak explains: 
The great thing about having Girls Rock Camp as a model, you know, it's not a figurative share your voice. It's literally you have to be on a microphone, you have to be loud, in order to finish your week off and be in the band. So [GRR] is such a great vessel for building self-confidence and really just putting yourself out there [...] whether you are a musician or not, even if you never pick up another instrument ever again, it's like, I had to speak into a microphone and I had to be really loud or play really loud. And I think that's really important, and I don't think we say that enough. (Danielle 2017)

The idea that a camper is asked to put herself out there in such a public way (in the final showcase where all of the campers perform at the end of the week), is often simultaneously quite scary and yet confidence-building, as Danielle suggests. Thus, it makes sense that many of the instrumental teachers and band coaches highlighted this idea of constantly needing to reassure the campers that it was not only okay to make noise, but also, that they were encouraged to speak up loudly, and to support each other in doing so. Melanie Hankewich (aka Belle Plaine), band coach and voice teacher, emphasized both the need to be loud and the significance of encouraging one another as she describes her process:

With the band it was really about making noise, and then when we got to making noise it was about tuning and making sure we all knew how to tune, because we were all going to make noise at the same time. And from there it was about fostering creativity with each other and making sure that we were all supporting each other's ideas, taking them seriously, and I feel like it was really effortless with the groups that I had. (Melanie 2017)

During a discussion held a few months after the completion of the first camp, Melanie clearly articulated the ongoing struggle of having her voice heard, and being recognized for one's expertise, experience, and knowledge as a professional musician. She observes,

\begin{abstract}
As a woman in the industry, I have more experiences than I like to admit about saying something three times and it not being heard, and then having it said from somebody of the male gender and everybody hears it. And so, we still have a long way to go, and as a professional in the industry [...] My work is to continue being vocal, not being frustrated, not writing people off, and believing that people will change; because if you don't, you're lost, we've already lost the battle. (Melanie 2017)
\end{abstract}

For both the campers and the crew, GRR enabled a space for discussing these kinds of sexist behaviours and the gendering norms that continue to be rampant both within and outside of the music industries (also discussed in detail by Ali 2012).

For the women, female-identified, trans, and non-binary persons who organize and volunteer with GRR, one of the key goals is to find strategies to assist in the removal of barriers and dismantle oppressive norms for girls and female-identified persons within the context of rock (and other genres). From learning to play an instrument, to forming a band, writing a song collaboratively, and performing in the final showcase, the campers collectively engage in processes that enable agency. Ultimately, they find themselves in an environment where their voices are respected and their contributions valued. When discussing her experience, one of the GRR campers remarked on how this made her feel: 
It's been good. Sometimes it's awkward when it's more boys than girls, or yeah, cause it makes me feel left out. In this camp, there are a lot of girls and I feel welcome and I feel happy because I'm around all these strong people, and I feel awesome. (Carly (pseudonym) 2017)

The GRR crew come to the camp with their own positive and negative experiences of the music industries, which is what motivates them to participate in the camp and to become mentors. One of Amanda's primary reasons for organizing GRR was the lack of women she sees on stage:

I always heard about Girls Rock Camp, and I was actually down in Austin at South by Southwest hanging out with Elsa, who is one of the organizers in Saskatoon. We were talking about the fact that of a four band bill we were the only two women on the stage that night, and it just kind of got me thinking about how many more of these camps we need happening. (Amanda 2017)

For many of the participating musicians, a lack of representation within their music scenes is a common experience. In her book Frock Rock: Women Performing in Popular Music, Mavis Bayton explores the "sociological factors that stop women from forming bands [...] material constraints like lack of access to equipment and transport, and the 'policing' of female leisure, along with ideological constraints like "the hegemonic masculinity of rock music-making'" (1998: 88). Although Bayton was writing this in 1998, her rationale for such a gender gap within the music industries continues to be prevalent in both the performance side, as well as the more technical sides of popular music (for further discussion of female identified performers' exclusion within the performance and technical side of the industry, see Marsh 2007 and Hancock 2017). Brittany MacFarlane works for Sask Music and is the volunteer coordinator for GRR. For her the question of underrepresentation, especially in Saskatchewan, proved challenging when trying to seek out women to fill particular positions in the camp. Her subsequent frustration is evident, as she states:

I think instilling confidence in [the campers] and assuring them that there are roles for them but also shedding light on the fact that women are underrepresented is key. Like for this camp, two of the things we struggled with were finding a woman to run the soundboard for our showcase, and also a woman to record [audio engineer] on Friday. So, there are opportunities, but it sucks that we couldn't find those people. (Brittany 2017)

The technological side of the music industries (audio engineering, sound tech, production, et cetera) has historically been an area dominated by men in spite of the innovative and ongoing contributions to this realm made by women (see Rodgers 2010 and www.PinkNoise.org). Play Your Gender (dir. Clattenburg 2016), a documentary (led in part by Canadian artist Kinnie Starr), focuses on the realities for women within the music industry in North America. The statistics shared in the documentary are illuminating. How is it that women only "represent $5 \%$ of music producers"; "less than 20\% of songs are written by women"; and "only $15 \%$ of record labels are majority owned by women"?. Encouraging more girls and women to participate in the industries is a common strategy presented by a number of the artists interviewed for the documentary (and from GRR) as a means to help circumvent the sexism and severe gender imbalance.

When asked about what kinds of advice were given to the campers to encourage their participation in the local music scene, Cassandra Ozog, a vocal coach, 
explained that although the realities can be tough, her advice presented the importance of supporting one another:

You don't want to paint that dark of a picture for them, but Melanie and I have been definitely talking to them about how there are not a lot of ladies out there in the music industry. And that's changing but when you're first starting out it's going to be a lot of guys. There are going to be guys in the band, doing sound and/or the managers, and doing all those things. So we've tried to give them some advice about supporting each other and supporting other women and not being competitive with other women because there is room for all of us; because there are not a lot of us, right? (Cassandra 2017)

Within the GRR crew, artists from across genres opened up about their experiences and the impacts of the "hegemonic masculinity of rock [indie, country, punk] music-making" (Bayton, 1998: 88). Melanie reflected on working with other women musicians, as well as artists from other disciplines, as a way to shift the landscape for herself. She explains,

Sure I have a female bass player and I work with visual artists and administration personnel that are female. Aside from that many of the bookers and many of the people I'm trying to attract industry support from - agents, managers, labels - are male. And yeah, you can really feel that your expertise is questioned. I feel that I really need to overcompensate with my confidence. It's such a boring cliché thing to say, but my male counterparts seem to have their opinions accepted as truth when they are spoken; whereas mine need to be reiterated. For example, my knowledge of gear needs to be reiterated. All of those structures are frustrating to be a part of. So just being able to encourage young women to be secure in their knowledge is important to me here and outside of this camp. (Melanie 2017)

For Melanie, knowledge is power. Writing and performing her own songs and knowing about the technological aspects of gear (including a sound board, amps, mics, tech set up, et cetera) and recording has helped her productively navigate some of the sexism she experiences.

Another collective experience among the GRR crew was an ever-present attitude of disbelief that these women were members of the band. Cassandra remarked on this when asked about her experiences as a musician in the punk scene in Saskatchewan:

If you are playing in the band, they'll ask you where the merch table is. They just assume that you are a girlfriend who has gone on tour with her boyfriend and you are just going to be the merch girl. So either you are the merch girl, you are a girlfriend, or you are both. And that was consistent across the board and usually that stopped once you got on stage and actually performed and did what you did and were good at it - but sometimes it didn't. (Cassandra 2017)

To be relegated to "merch girl" or "girlfriend" is a common thread. Jen Moser Aikman, drum teacher and band coach, adds: "there are fewer of us [women drummers] so I talked about how a lot of time [when I'm] playing shows people will think you are helping your boyfriend carry his gear in". Based on the sexism she experiences as a drummer, Jen's advice to the campers included, 
That's why it's important for us to handle all our own gear and be able to lug our kick drum [...N] ot that it's' not okay if you can't. But to be able to handle it and be able to know enough and just be confident enough to know that you are as capable as anyone else is key. (Jen 2017)

If these are the realities for women in the music industries, how does one approach a role of mentorship? For many, representing gendered realities found within the music industries is a fine balance. Cassandra unpacks the complexities of this aspect of mentorship:

I was always really lucky, I always had a really supportive group of people who I played with, a group of guys, who I think, sometimes, were like, "oh god, here we go" but they also always had my back, and if I was like I'm walking off stage, they would follow me. So, I think trying to encourage [the campers] to build that type of environment around them, encourage them to stand up for themselves when those things are happening. But yeah, it's tough. [...] I think about the first time, I had somebody yell, "show us your tits" on stage. I was probably fifteen or sixteen, and at that time, you're like in the zone, and just like, "don't think about it, don't think about it." But you're kind of shaken up and you're trying to make a joke about it [...] but then when it happens to you when you are older, you have a far different response, where you are like, okay, well I'Il just find that guy after the show, and you hope that people will shut it down, people who are nearby. [...] But it's hard to think about those girls experiencing that so you just hope that not just in music, but maybe in life, that they'll be strong enough in life to shut that shit down. But you can't bring that all into the room [at camp], you have to be like, "oh, we're singing Katie Perry now. We're really excited and happy!" So, yeah, it's tough. (Cassandra 2017)

Kristina positions the impacts of sexism within the context of overall wellbeing. In her case, she began her music career at a young age and she had little experience on how to navigate systemic sexism within the industries. For Kristina the fact that these young campers are given a context and a language to talk about what they are potentially going to encounter within the industries is significant. She explains,

I've been a musician for ten years, and I've experienced so much sexism in that time, and I think that it's had a pretty bad effect on me and the other woman in my band - I think a lot of stress and anxiety and all that stuff. You know I started [performing with the band] when I was 18 and experiencing all that before I understood it. It's not like it's overt. It's micro aggression types of things. I didn't understand what that was, and I think I really internalized it and we were told we were being too sensitive, because guys don't see it, or don't see the frequency of it, so we were always told we were being too sensitive. So this gave us the message that there was something wrong with us, rather than something wrong with what was going around us. I really wish I had something like [GRR] to at least have that language or understanding of what kind of situation I was going into, or at least the dynamic. I think that would have changed things so much for me. My confidence would have been much better if I had understood that from the start, instead of five years into it. (Kristina 2017)

\section{Collectives, Mamas, Friendship}

Sometimes if you don't fit into the community you see, another option is to just build your own. (Amber Goodwyn (aka Natural Sympathies), member of the GRR organizing crew 2017) 
Within feminist discourse there is often a strong emphasis placed on female collectives, networks, and friendships when strategizing to resist and disrupt normative systems of power. Lucy $\mathrm{O}^{\prime}$ Brien argues that being in a girl band, no matter the length of time, offers a place for learning the tools for feminist activism. She states: "So musical cohesion, friendship, and teamwork - whether it's experienced as a short burst like The Runaways or over decades like Girlschool are all great skills to have in learning the foundations of sisterhood, solidarity, feminine agency, and sharing power" (2016: 17). As both Powers (2017) and O'Brien highlight in their work, women and girls have gathered together to form powerful collectives and have benefited from those whose feminist activism has gone before. GRR, as a newly formed feminist collective, can be transformative on many levels as it actively works towards the empowerment of girls, women, femaleidentified, trans, and non-binary persons, through the creation of feminist music spaces in Regina. Amber articulates the importance of such spaces as she discusses her own musical journey:

\begin{abstract}
When I was a teenager I had the opportunity to be in radical feminist spaces, and I've always been a pretty confident person. I always felt like if there's something I wanted to change outside of my own window, I should go and make that change happen, make the world that I want to live in. [...] I moved to Regina from Montreal about five years ago, and when I moved I left behind all the [music] projects that I was involved with, and all my friends and my band, which broke my heart, and I didn't play music for two years. I fell pregnant, and all that stuff went by and I learned from it - and then I just felt like I really wanted to once again be a part of the kind of community I like to be a part of, which was, a lot of strong women and trans folk making music and making noise and taking up space. And I had been thinking about Girls Rock Camp, [...] and so I just immediately started emailing the organizers and tried to get involved as soon as I possibly could. Because, this is exactly the kind of community I want to see and help build in Regina. (Amber 2017)
\end{abstract}

Amber's situation is one that illustrates the kind of loss that occurs when one moves away from their feminist communities, and the need to rebuild or find supportive environments to create and play in. This is also a narrative of the potential impact that feminist mothers who are musicians may have on the next generation. O'Brien (2016: 17) argues that because "current female musicians have feminist mothers who are music fans or in bands", they are "building on a culture that, $[. .$.$] is set to rival the male canon". When discussing the rationale for the$ creation of GRR, many of the organizing crew (some who are mothers now) opened up about how they wished GRR had existed for them in their childhood. For COfounder Danielle, it was about the desire of her "11-year old self" and the dream for her young daughters to have access to GRR once they are older. Danielle explains:

I'm not a musician. I can't relate to that experience, but I wanted to be part of it sooo bad. So I was thinking, 11-year-old me would have just died and gone to heaven, right? So, I just kept kind of watching and pursuing it. And then you know, having two young daughters and seeing the opportunities that these camps brought out. [...] it's open to so many good things, so many good messages. [...] It's putting yourself out there. It's being creative and actually learning a skill... it's very accepting. [...] there's just, every type of person who participates in these camps. I just felt like, this needs to happen in our city. (Danielle 2017) 
Creating a feminist music collective and feminist music spaces like GRR is much more than mamas living vicariously through their daughters. In relation to GRR, Amber states, "there's the element of building community among young people and teaching them, peer to peer, to become a strong community among themselves" (ibid.). Reflecting specifically on the GRR crew she also articulates another layer of activism: "But then there's also us as adult women and trans folk learning to work equally with one another and share ideas and think concretely about how we can make our city more welcoming for young people". As Powers (2017) notes, "[t]hroughout rock and roll's history, women have protested [the] status quo even as they've found a way to feel free within it. Every generation has seen those who fight to raise each other's consciousness and imagine a new reality".

Thinking about this new reality, many of the participants have discussed with me the significance of what it has meant to come together under the GRR framework, and how an unexpected and important outcome has been the evolution of a network of supportive collaborators, the fostering of new friendships, and the creation of all-girl / all-female identified bands. And if, as Julia Downs (2012: 13) argues in her book Women Make Noise, "all-girl bands are a powerful force for cultural change", GRR is contributing to this cultural change within and on the outside of the music industries.

\section{Expanding Musical Knowledge}

I've had people say some pretty horrific things to me from the audience. Take your pick of things of anything that has ever been yelled at a woman who has ever been on stage, and it's shitty, and sometimes it breaks your heart a little bit to think about these girls who are 11,12, and 13 and they are just so jazzed to be on stage. Oh man, this is going to happen to you. I hope it doesn't but realistically it will. So I think just by getting them to be confident in themselves and encourage each other and be supportive so that if it happens to them they can stand up for themselves, and they can build a group of musicians who will stand up for them. (Cassandra, GRR Vocal Teacher)

To make substantial changes within the music industries, a serious growth in the number of women participating at various levels, and especially in positions of power, seems necessary. Girls and women need to know that there are many possible ways to contribute, rather than being relegated to the very few femaleidentified roles. Moreover, to be aware of the multidimensional nature of the music industries and its various roles is critical to be able to break through. In her call out for transformation of the industries, Powers (2017) makes the argument that "more women need to lead, not just as the faces and voices of rock and roll, but as its producers, it engineers, its tour managers, its architects". Grass roots initiatives like GRR contribute to this shift by creating feminist spaces for music making, promoting role models for young people to identify with, providing support through collective engagement, as well as offering mentorship. For the GRR organizing committee, the inclusion of a mentorship model was, and remains, a primary goal of the camp. Mentoring young campers can have a distinct impact on helping young women and female-identified persons make their way into the industries that have been less accessible. Through the process of mentorship, one has the ability to teach the concept of building community and creating feminist spaces to empower and support others. 
When discussing these strategies, musician Meghan Nash (guitar teacher and band coach) offers the following:

I think it's important for young female identifying folks to see strong female identifying - not strong, sorry, because sometimes I struggle with that word of how we always have to be strong. I think it's important for youth to see women doing things especially [...] to be able to see female identifying folks be creative, be working in a scene, in an industry. The music industry is still SOOOO male dominated and there's lots of toxic masculinity within it. The way it's structured too. Things like [GRR camp] are super important, so they [the campers] know it's an option for them. So they're like I know I can make a punk band. [...] It's been really neat as a band coach to see young folks working together and taking instructions in regards to the band dynamic. Like that's been really cool. I have two guitarists in our band and yesterday, they were like, we really need to work with each other and listen to each other. I was like YES! (Meghan 2017)

Participating and becoming mentors in the first GRR camp has had a profound impact on the musicians and members of the organizing crew. Throughout the interviews and daily discussions during the wrap up meetings held at the end of each day, the team opened up about how the camp was affecting them. In an interview, Kristina even expressed that her desire to play again returned as a result of working with the campers:
Me and my co-band mate have a lot of anxiety and stress around music and we've taken a break and for like a few months and I really haven't touched my instrument in that time because I just associate so much stress with it. But already being in this environment has inspired me a lot and given me so much more - I don't know - I'm excited about music again which hasn't happened in a while and I think sometimes you get inspired by a female musician and then you are surrounded by all this other stuff so to be in a situation like this for a week, it's like all these awesome girls just want to rock out and these amazing female musicians and you just focus on making music and you don't have to deal with the other stuff. That has been such a weight off my shoulders; I didn't even realize. I guess it gets so overwhelming to think about what the music industry is like, but then to see a huge group of girls, you think maybe it will be different, I don't know, that's pretty exciting. (Kristina 2017)

One of the key benefits of the GRR camp came to the surface when, on day one, these young girls had an instrument put in their hands and were immediately encouraged and supported to play and write a song together. Moreover, they also knew that at the end of the week they would record and then perform their songs in the showcase to an incredibly supportive audience made up of family and friends. The impact of such a positive first musical performance experience is immense. Dougher (2016: 196) argues that "performing rock music in front of an audience, literally rocking, becomes an opportunity for girls to assert and broadcast their belief in themselves [...]". For the GRR crew, the ability to foster and create a positive first experience of performing on a "real" rock stage for the girls was a powerful moment. Beth offered her reservations about being too up front about the realities female-identified performers face in the music industries:

I haven't been bringing that negative part of it, because they haven't had to experience it and I don't want them to and so giving them their first experiences on the instruments or with the technology being ones where they are valued 
and their knowledge is valued and, their experience is legitimate, and in every moment trying to give them that first experience so they know it's not normal when they are treated otherwise. You know, even witnessing one of the campers going up to Amanda when she was at the soundboard, and to see Amanda open to this kid and let her immediately touch everything on the board and letting her know what it meant, it was [...] I almost cried because that's going to be her first experience instead of being closed off from the technology. And that was at the beginning of the week, and I kind of took that as my approach, letting their knowledge be legitimized, wherever they are at with it, and yeah, I just want them to know it's not normal to be devalued. (Beth 2017)

The process of valuing the girls' experience through mentorship also occurred as the campers' knowledge of female artists expanded. For many of the campers, their musical tastes are informed by commercial pop music; music marketed primarily to young tweens. Although there is definite value in this music, and young girls have agency around their musical tastes, many of the campers make decisions on aesthetic values based on what they have been introduced to in their home, by their peers, or from mediated venues on line, television, or radio streams. Melanie found this, especially while working with the group of campers who chose the role of singer. She explains:

Yeah, with the singer most of what my group was listening to is mainstream music, which is fine, it's what I grew up listening to, but I thought this camp was such a wonderful opportunity to tell them about artists that we were all excited about, you know, you did a presentation, you talked about Björk, and I think, we haven't talked about Tori Amos yet, but that was like part of our background, like Grace Slick came up, and all of these like, amazing women through the ages, just kind of kept coming up and I thought that was one of the most powerful things of the rock camp is, like, it's like Katy Perry, yeah, I'm cool with Katy Perry, but I also want you to know who these other artists are, and maybe you'll align with some of those ideas too, maybe, like, that will spark other ideas around creativity. (Melanie 2017)

Archetypes assigned to women in the music industries and entrenched deeply within celebrity culture were also integral to this discussion of expanding knowledge. A number of the musicians reflected on how they struggled with attempting to fit one of these archetypes, and consequently, felt like an outsider. Amanda spoke at length about her experiences of trying on the various roles only to finally come to terms with who she is and how she is different from these defined norms. She reflects on her process:

Well I know I don't fit into the dude thing but maybe I do and maybe I'II try for a while. Maybe I'Il be the most crass person in the room for a while. [...] Maybe I'll be more loose with my sexuality than I feel comfortable with because maybe that's who I'm supposed to be. Maybe I should lose fifty pounds. Maybe I should wear high heels. [...] It took me awhile to circle back to the core of who I am and being okay with that. Being okay with showing that to the world, because at the same time, not only am I struggling with that internally, I'm also getting up on stage in front of thousands of people. [...] That's why I was so attracted to Girls Rock camp, because I'm just figuring this out, and if I could and not just tell people, but show people some different ways to think about these things, and have these strong women come in and do different things, like parkour, pow-wow, songwriting, and if we can just integrate that into normalcy, then that would be great. (Amanda 2017) 


\section{Feminist Interventions}

It's been really cool because all of us are girls trying to make our dreams come true and a lot of boys will try to stand in our way and tell us that we can't do it, but all the girls here don't seem like they'll take that as an answer. That's why I really like being in this Girls Rock Camp. (Kaitlyn (pseudonym) 2017)

Although this was only the inaugural year for GRR, there have already been some tangible outcomes. From my observations, it is clear that the campers were empowered, inspired, and learned how to play the basics of an instrument, compose a song collaboratively, and perform in an all-female band on a real rock stage. GRR has established a resource for organizers, teachers, band leaders, musicians, and volunteers to carry forward in the future. Furthermore, the beginnings of a strong feminist collective committed to creating real change for girls, women, female-identified, trans, and non-binary persons within the music industries in Regina and beyond has been firmly established. Thus, possible future outcomes can be considered with a sense of optimism. As Meghan suggests,
I feel like I'll really see [the impact of GRR] on Saturday [at the showcase] or we'll all see it in the community in the next five to ten years you know what I mean - it's going to be really interesting to see how many of the campers will pursue music. It's been amazing to see the amount of workshops they have just in terms of taking up space - it's so easy to apologize just for existing as a woman you know. Sometimes I used to think that was a Canadian thing but now I'm like no, a lot of this apologizing is just about how we are culturally raised - so just taking up space, even. I think that's so powerful. Encouraging the campers to be loud. To make sound. To take up space. To be confident. To give opinions. To listen to others [...] watching the campers encourage each other has been really cool. (Meghan 2017)

Narratives of shared experience, strategies for resistance, and feminist music collective creation are integral to understanding how GRR can contribute to a reorganizing of the music industries. As Nyala Ali (2012) argues in her work on the connections between Riot Grrrl and Girls Rock Camp: "Mindful of the societal constraints under which women, especially young women, are given space to operate, Girls Rock Camp challenges girls to take risks with their identities both as women and musicians" (157).

The GRR crew and its inaugural camp are both provoking and creating change in a multidimensional way at a local level while simultaneously participating within a wider campaign of revolutionary actions. When describing how Girls Rock Camp is feminist, and often embodies an implicit feminism as activist strategy, Danielle M. Giffort argues: "Production and performance of rock music [within these camps] functions as a political tool for personal empowerment and collective resistance" (2011: 576). For GRR, the engagement of music making within this environment is indeed a promising feminist intervention.

The experiences of the women, girls, female-identified, trans, and non-binary people involved in GRR are both rich and complex. Further research and analysis on Girls Rock Regina including the second camp, future Women's Camps, as well as ongoing programming and events throughout the year will contribute to more discussions on the impacts that community arts-based initiatives have on expanding the possibilities for women in the popular music industries. This study is the 
beginning of a substantial 5-year research program which will focus on how Girls Rock Regina, and two of its sister Girls Rock affiliates in western Canada, including Girls Rock Saskatoon and Girls Rock Winnipeg, are empowering campers, as well as the women, trans, female-identified, and non-binary persons who are championing this activist movement.

\section{Endnotes}

1 This research project went through the University of Regina ethics review process. Everyone who participated in the interviews for this research was informed that their interviews could be used for publication and that anonymity was not guaranteed. Campers, however, were underage participants, and so pseudonyms are used for their responses in this paper.

\section{References}

\section{Bibliography}

Ali, N., 2012. From Riot Grrrl to Girls Rock Camp: Gendered Spaces, Musicianship and the Culture of Girl Making. Networking Knowledge, Volume 5, Issue 1, 141-160.

Apolloni, A., 2008. Rebel Grrls in the Classroom: Vocality, Empowerment and Feminist Pedagogy at Rock and Roll Schools for Girls. UCLA Centre for the Study of Women. https://escholarship.org/uc/item/0b18q8fb

Bayton, M., 1998. Frock Rock: Women Performing in Popular Music. Oxford: Oxford University Press.

Butler, J., 2005. Giving an Account of Oneself. New York: Fordham University Press.

Cloonan, M., Homan, S. and Cattermole, J., 2015. Popular Music Industries and the State: Policy Notes. New York: Routledge University Press.

Dougher, S. 2016. When Loud Means Real. In Voicing Girlhood in Popular Music: Performance, Authority, Authenticity. Eds. A. Adrian and J. Warwick. New York: Routledge, 191-207.

Downs, J. 2012. Introducing the All-Girl Band: Finding Comfort in Contradiction. In Women Make Noise: Girl Bands from Motown to the Modern. Ed. J. Downs. Twickenham: Supernova Books.

Giffort, D. M., 2011. Show or Tell?: Feminist Dilemmas and Implicit Feminism at Girls' Rock Camp. Gender \& Society, Vol. 25, No. 5, 569-588.

Hancock, M. 2017. Lick My Legacy: Are Women-Identified Spaces Still Needed to Nurture Women-Identified DJs?. Dancecult: Journal of Electronic Dance Music Culture, 9(1), 73-89.

Kay, S. 2017. Rockin' the Free World!: How the Rock \& Roll Revolution Changed America and the World. New York: Rowman \& Littlefield.

Marsh, C. -

2007. In and Out of the Classroom: Reflections on Identity, Technology, and the Radio Project. Intersections: Canadian Journal of Music, 26(2), 81-96. 2009. What it Feels Like for a Girl: Metaphor, Transgression, and the Triumph of Madonna's Imaginary Cyborgs. Atlantis: A Women's Studies Journal, 34(1), 111-120.

2019 (forthcoming). No Matter How Old, How Young, How Sick; I Mean Something: Peaches, Sex, and the Ageing Female Body. In Hearing the 
Political: Queer and Feminist Interventions in Popular Music. Eds. S. Fast and C. Jennex. New York: Routledge.

Marsh, C. and West, M., 2003. The Nature/Culture Binary Opposition Dismantled in the Music of Madonna and Björk. In Music and Technoculture. Ed. René Lysloff. New England: Wesleyan Press, 182-203.

O'Brien, L. 2016. I'm With the Band: Redefining Young Feminism. In A. Adrian and J. Warwick Eds. Voicing Girlhood in Popular Music: Performance, Authority, Authenticity. New York: Routledge, 15-36.

Powers, Ann. 2017. "Don't Call Me Honey: In 2017, Women Confronted the Deep Roots of Rock's Boys Club." National Public Radio Music (December 12). Retrieved from: https://www.npr.org/2017/12/12/568728840/won-t-getfooled-again-in-2017-women-confronted-the-deep-roots-of-rocks-boys-club

Rodgers, Tara. 2010. Pink Noise: Women on Electronic Music and Sound. London: Duke University Press.

\section{Web Sources}

PinkNoise: www.pinknoise.org Accessed 13 August 2018

\section{Filmography}

Play Your Gender. 2016. Dir. Stephanie Clattenburg. Nava Projects.

\section{Interviews}

Amber Goodwyn. 2017. Interview by Charity Marsh, Regina, 29 July. Amanda Scandrett. 2017. Interview by Charity Marsh, Regina, 2 August. Brittany McFarlane. 2017. Interview by Charity Marsh, Regina, 24 July. Beth (pseudonym). 2017. Interview by Charity Marsh, Regina, 29 July. Cassandra Ozog. 2017. Interview by Charity Marsh, Regina, 26 July. Carly (pseudonym). 2017. Interview by Charity Marsh, Regina, 27 July. Danielle Sakundiak. 2017. Interview by Charity Marsh, Regina, 3 August. Jay Kovach. 2017. Interview by Charity Marsh, Regina, 25 July. Jen Moser Aikman. 2017. Interview by Charity Marsh, Regina, 26 July. Kaitlyn, 2017. Interview by Charity Marsh, Regina, 27 July. Kristina Hedlund, 2017. Interview by Charity Marsh, Regina 27 July Meghan Nash. 2017. Interview by Charity Marsh, Regina, 25 July. Melanie Hankewich. 2017. Interview by Charity Marsh, Regina, 25 July. 